\title{
Artificial Intelligence and Human Rights: Are There Signs of an Emerging Discipline? A Systematic Review
}

\author{
Emmanuel Kabengele Mpinga (D)', Ngoyi KZ Bukonda ${ }^{2,3}$, Said Qailouli', Philippe Chastonay ${ }^{4}$ \\ 'Institute of Global Health, Faculty of Medicine, University of Geneva, Geneva, Switzerland; ${ }^{2}$ Department of Public Health Sciences, Wichita State \\ University, Wichita, KS, USA; ${ }^{3}$ Faculté des Sciences de la Santé, Université Pédagogique Nationale, Kinshasa-Ngaliema, Democratic Republic of the \\ Congo; ${ }^{4}$ Health Promotion Switzerland, Bern, Switzerland
}

Correspondence: Ngoyi KZ Bukonda, Department of Public Health sciences, College of Health Professions, Wichita State University, 1846 Fairmount Street, Wichita, KS, 67260-0043, USA, Email Ngoyi.bukonda@wichita.edu

\begin{abstract}
Aim: Our systematic review seeks to understand the linkages and reciprocal relationships between the artificial intelligence (AI) and human rights (HRs) and to unveil the signs of emergence of a new discipline at the crossroads of these two disciplines.

Background: AI and HRs have evolved in parallel as two fields, with AI technology engineers eventually interested in the consequences of their products on HRs, while more recently HRs experts have been exploring the benefits and threats of AI technologies on the protection and promotion of HRs.

Methods: A broad range of databases within the fields of legal sciences, social sciences, health-care sciences and the more general sciences practitioner base "Web of Science" were explored. Articles were selected according to strict inclusion/exclusion criteria and systematically analyzed regarding their content and authorship.

Results: The crossroad between AI and HRs is a dynamic field where researchers from different disciplines have been exploring issues such as autonomous lethal weapons, privacy protection, discriminatory decision-making in the insurance and finance systems, intellectual property, and legal personality of the robots. Signs of the emergence of a new discipline were identified.

Conclusion: Identifying appropriate strategies to consolidate this emerging discipline seems necessary: one could be the development
\end{abstract} of academic programs at the crossroad of these two fields.

Keywords: artificial intelligence, human rights, scientific discipline, systematic review, emerging disciplines

\section{Introduction}

Over the past decades Artificial Intelligence (AI) has invaded and transformed our way of life, of communication, of care and of education, as well as our industrial production procedures, our leisure time, our cultural realizations, even our intimacy. ${ }^{1-4}$

From a strategic and organizational perspective, it should be recalled that the political, economic, military, regional or global organizations not only are aware of the potential but also of the possible threats of the AI on our societies. Indeed, in 2015, the United Nations opened in The Hague the Center for Artificial Intelligence and Robotics at the United Nations Interregional Crime and Justice Research Institute (UNICRI); ${ }^{5}$ and in 2018 it convened an international conference bringing together 32 agencies of the UN system to serve as a platform for exchanges between the United Nations and its various branches on its future AI strategy. ${ }^{6}$

After setting up its strategy on the AI in April 2018, the European Union (EU) made two significant steps forward, by organizing two months later a high-level experts group on the subject and by publishing in February 2019 its first coordinated action-plan ${ }^{7,8}$ promoting trustworthy AI through ethics guidelines, policy and investment recommendations. The proposed ethical orientations are: 
Develop, deploy and use AI systems in accordance with the following ethical principles: respect for human autonomy, prevention of any infringement, fairness and explainability. Recognize and resolve potential tensions between these principles.

Pay particular attention to situations concerning more vulnerable groups such as children, people with disabilities and other groups historically disadvantaged or exposed to risk of exclusion, and in situations characterized by asymmetries of power or information, by example between employers and workers, or between businesses and consumers.

Recognize and be aware that AI systems certainly bring considerable benefits to individuals and society, but that they also present certain risks and may have negative impacts, including impacts that may be difficult to anticipate, determine or to be measured (for example impacts on democracy, the rule of law and distributive justice, or on the human mind itself). Adopt appropriate measures to mitigate these risks, if appropriate, in a manner commensurate with the magnitude of the risk. ${ }^{9}$

Which brings us to fundamental human rights (HRs). Indeed, those recommendations underscore the link between AI and basic HRs, be they considered:

- In a naturalistic perspective, ie. human rights are rights possessed by all human beings (at all times and in all places), simply in virtue of their humanity. ${ }^{10}$

- In a legalistic perspective, ie, the existence of a series of law-making international instrument enumerating, analyzing, and clarifying generations of human rights such as The International Covenant on Economic, Social and Cultural Rights, The International Covenant on Civil and Political Rights and The Optional Protocol to the Covenant on Civil and Political Rights. ${ }^{11}$

- In a jurisprudential perspective fundamental human rights are rights that take precedence over all other rights as suggested by various authors, ${ }^{12,13}$ which in turn implies justiciability of HRs. ${ }^{14}$

These different perspectives help consider human rights as universally recognized and accepted principles that should allow everyone to realize his full potential of life in an environment of freedom, justice, security and peace. ${ }^{15}$

As for the link between AI and HRs, Liu and Zawieska in 2017 reported, while studying the impact of the reversal of power between human rights and new technologies on the protection of fundamental human rights (HRs) that artificial intelligence (AI) is on the cusp of exerting a growing influence for the promotion of HRs, as well as enhancing potential violation of HRs. They argued for a new set of HRs capable to deal with the robotics and the AI. ${ }^{16}$ In 2018 , Chakraborty \& Bhojwani critically analyzed the effects of AI on HRs under the angle of economic structures, labor relations, job, as well as worktime and remuneration models, which are all expected to undergo major changes due to an increased use of AI. ${ }^{17}$ Reisse studied similar aspects while taking a time perspective: the short-term effects relate to the use of discriminatory algorithms affecting nearly all the rights contained in the Universal Declaration of Human Rights (UDHR); the medium-term challenges notably include changes of working conditions, possibly excluding from work large parts of the population; on the long-run there is the perspective that humans might have to work (and live) with machines which are intellectually and morally superior to humans. ${ }^{18}$ Reisse insists upon the necessity of instigating more interest in $\mathrm{AI}$ within the human rights community. ${ }^{19}$

In an academic perspective, this raises several questions, notably:

First, what is the level of knowledge regarding the links between AI on HRs (and vice versa)?

Second, are there signs of the emergence of a new scientific discipline that encompasses AI and HRs?

Third, what are the conditions susceptible to strengthen research and action specifically addressing the link between AI and HRs?

Our study explores the linkages and reciprocal relationships between the AI and HRs and looks for signs of the emergence of a new discipline at the crossroads of these two disciplines through a systematic review of the scientific literature over the past decades. 


\section{Methods}

\section{Research Design and Strategy}

The study is a systematic review of literature. The used search strategy is based on the well-established methodology referred to as Preferred Reporting Items for Systematic Reviews and Meta-Analyses (PRISMA) model and it unfolds in 4 steps: ${ }^{20}$

- First, key words covering the two areas of research are identified as well as their synonyms and related concepts.

- Second, a search strategy including the identified key words is formulated.

- Third, this search strategy is applied with any relevant adaptation to the modalities or requirements of each database.

- Fourth, the articles/publications obtained from the query of each database are pooled to generate a single file that can be used for detailed analyses.

In the present case, the search strategy (including the key words used) has been formulated as follows "artificial intelligence" or "robot" or "intelligent agent" or "machine learning" or "data mining" or "autonomous vehicles" or "autonomous weapons" or robotics or "artificial general intelligence" "super-intelligence" or "digital society" or "digital era" or "computer reasoning" or "machine intelligence" or "artificial intelligence system" AND "human rights" or "human right" or "civil rights" or "political rights" or "economic rights" or "social rights" or democracy or "fundamental rights" or "freedoms".

The equation has been applied to a broad range of databases falling within the fields of legal sciences (LexisNexis, Westlaw and HeinOnline), of International Bibliography of the Social Sciences (IBSS), of health care sciences (Embase) and on the more general sciences practitioner base known as "Web of Science".

The literature search was carried out by two groups of experts of the libraries of the Faculty of Medicine and of the Faculty of Social Sciences and Humanities of the University of Geneva between November 2019 and January 2020.

The research covered a period of 70 years from 1 January 1949 to 31 December 2019 and was limited to work published in English and French. The whole process is synthesized in Figure 1.

\section{Exclusion Criteria}

A set of exclusion criteria to be applied were identified, ie: articles without abstract, press releases, newspaper editorials, technical reports, summaries of symposia, books, chapters, letters to the editor, glossaries, judicial decision, and duplicates.

\section{Analyzing Process}

Guided by the principles and best practices suggested by previous models, ${ }^{21}$ two of the authors (QS and EKM) designed a reading grid for each article. Based on this reading grid, the research team:

- Retained the year of publication, the names of the first author, the name of the journal, the country of residence of the first author such as identified or provided by the bibliographic references.

- Classified the journal in which the article was published in one or another of the pre-established categories which were Law journals, International Relations and Security journals, Human Rights journals, Ethics journals, journals of Sociology, engineering sciences journals, and others (biomedical and social insurance journals).

- Identified the design of each study through either self-contained indication in the title or any relevant classification made in the research database. The design of studies included review such as ethical, sociological, legal, political, epistemological, psychological, historical analyses as well as case studies, literature reviews and documentary analyses.

- Noted the major topics of AI addressed as well as the HRs mentioned. 


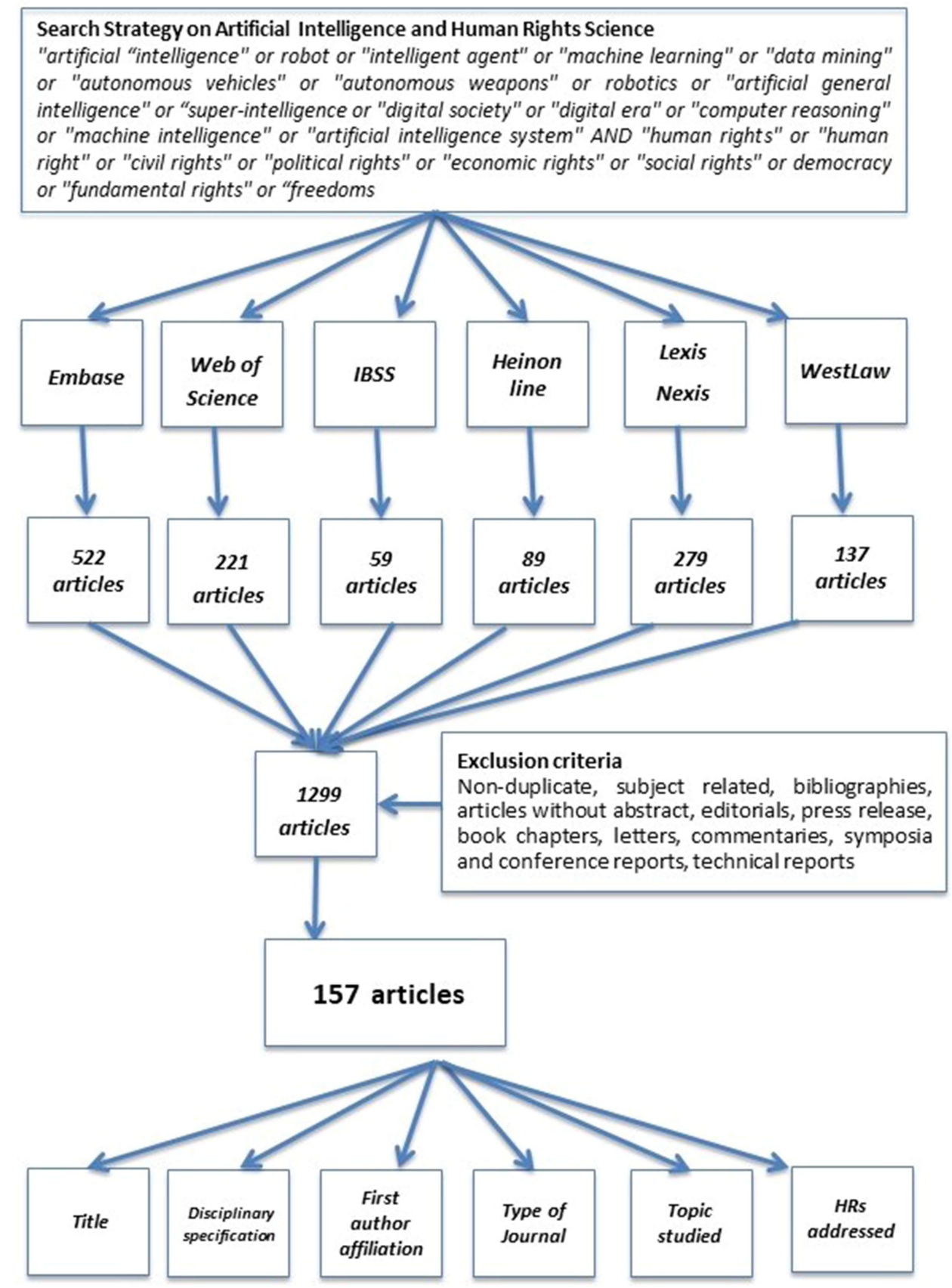

Figure I Research strategy and results.

- Created an Excel database containing, for each publication the elements of analysis presented above. One of the coauthors reviewed this database to prune any encoding error. The cleaned data were subsequently exported to IBMSPSS 19.0 for descriptive analyses.

\section{Results}

A total of 157 articles met the inclusion criteria out of 1299 articles. No article prior to $1994 \mathrm{did}$. All but one were written in English. More than half of the articles were published between 2017 and 2019 ( $n=90$ or 57.3\%). Approximately onethird (28\%) had been published between 2014 and 2016, and 15.2\% during the 1994-2013 period. The list of studied articles appears in Annex I. 


\section{Disciplinary Specifications}

The distribution of these articles according to their disciplinary specification can be summed up as follows: approximately half of the studies (51.5\%) were legal analyses, followed by political (16.5\%) and by sociological studies $(10.1 \%)$ whereas epistemological studies and literature reviews represent a smaller percentage ( $4 \%$ and $3.1 \%$ respectively). The remaining $14.8 \%$ include case studies as well as articles with a historical, psychological, or documentary perspective.

\section{Journals Where Articles Have Been Published}

Almost 7 articles out of 10 (68.1\%) have been published in law journals; $10.8 \%$ in journals specialized in international relations and security; $7.6 \%$ in human rights journals. The remainder of the articles appeared in ethics, sociology, biomedical, insurance and engineering journals.

\section{Institutional Affiliation of First Author}

Close to the half of all articles (46.4\%) were written by authors affiliated to an US institution; $11.4 \%$ by author from the United Kingdom and 5.73\% from the Netherlands. The remaining 36.3\% include work by authors from 24 different countries.

\section{Topics Studied}

Regarding the research topics studied in the various articles, $24.8 \%$ have explored concerns related to autonomous weapon systems. The second group has focused on the issues related to the collection, storage, analysis and use of big data (15.9\%). An approximative similar share of work (15.3\%) has focused on the use of algorithms in decision-making processes in various life sectors (justice, medicine, finances ...). The need for regulation has been studied in $12.1 \%$ of the papers. The issues related to robotics was discussed in $11.4 \%$ of the articles and the issues related to AI in the media in $10.2 \%$. Further topics included mobility issues or intellectual property rights for example (Table 1).

\section{Human Rights Addressed}

The right to life (21.4\%) and the right to security (19.4\%) are the most frequently mentioned rights, followed by the right of the privacy (14.3\%), and the right to justice (9.3\%). Less frequently, the right to health (4.3\%), the right to democratic participation $(4.0 \%)$ or the right to non-discrimination (3.6\%) and the protection of intellectual property $(3.6 \%)$ have been discussed in the various articles (Table 2).

Table I Topics Studied

\begin{tabular}{|l|c|c|}
\hline Topics & (N) & (\%) \\
\hline Autonomous Weapon Systems & 39 & $24,8 \%$ \\
\hline Big Data & 25 & $15.9 \%$ \\
\hline Algorithms & 24 & $15.3 \%$ \\
\hline Regulations & 19 & $12.1 \%$ \\
\hline Robots & 18 & $11,4 \%$ \\
\hline Media & 16 & $10,2 \%$ \\
\hline Self driving cars & 7 & $4.5 \%$ \\
\hline Intellectual property & 6 & $3.8 \%$ \\
\hline Geolocation & 2 & $1.3 \%$ \\
\hline Total & 157 & $100 \%$ \\
\hline
\end{tabular}


Table 2 Human Rights Addressed

\begin{tabular}{|l|l|l|}
\hline Rights Addressed & $\mathbf{( N )}$ & $\mathbf{( \% )}$ \\
\hline Right to life & 64 & $21.4 \%$ \\
\hline Right to security/safety & 58 & $19.4 \%$ \\
\hline Protection of privacy & 43 & $14.3 \%$ \\
\hline The right to justice & 28 & $9.3 \%$ \\
\hline Right to health & 13 & $4.3 \%$ \\
\hline Right to democratic participation & 12 & $4.0 \%$ \\
\hline General (all rights) & 12 & $4.0 \%$ \\
\hline Non-discrimination & 11 & $3.6 \%$ \\
\hline Intellectual property & 11 & $3.6 \%$ \\
\hline Right to work & 07 & $2.3 \%$ \\
\hline Right to information & 06 & $2.0 \%$ \\
\hline Right to personal identity & 06 & $2.0 \%$ \\
\hline Freedom of movement & 05 & $1.6 \%$ \\
\hline Humanitarian rights & 05 & $1.6 \%$ \\
\hline Right of election and eligibility & 03 & $1.0 \%$ \\
\hline Freedom of expression & 01 & $0.3 \%$ \\
\hline Right to food & 01 & $0.3 \%$ \\
\hline Protection against torture & 01 & $100 \%$ \\
\hline Total & 299 & \\
\hline & & \\
\hline
\end{tabular}

\section{Impact of $\mathrm{Al}$ on HRs}

Analyzing the content of the studied articles showed that the impact of AI on HRs was twofold: on one hand, there were identified opportunities, on the other hand, clearly identified threats (Table 3).

\section{Discussion}

To respond to the question of whether the results of our study reflect the emergence of AI \& HRs as a scientific discipline, it is important to look first at the concept of discipline and at the conditions for the emergence of scientific disciplines in general as well as at the fundamental characteristics of a scientific discipline.

\section{The Concept of Discipline}

A discipline corresponds to the structuring of professional and research practices around paradigms, which means that the concept of discipline is closely linked to the production of new knowledge. ${ }^{21}$ A discipline can also be seen as an institutionalization of teaching and research as proposed by Affergan et Valade. ${ }^{22}$

\section{The Concept of Emerging Discipline}

From the point of view of the history and sociology of science, scientific disciplines emerge in different ways: some grow in niches within established disciplines; other develop on the margins of two or more disciplines; some result from 
Table 3 Impact of $\mathrm{Al}$ on HRs

\begin{tabular}{|c|c|c|c|}
\hline $\begin{array}{l}\text { Application } \\
\text { Areas }\end{array}$ & Effects of Al & Protected Rights & Rights Under Threat \\
\hline I. Agriculture & $\begin{array}{l}\text { - Increased productivity } \\
\text { - Increased food security } \\
\text { - Improved food quality control }\end{array}$ & $\begin{array}{l}\text { Right to life; Right to health, } \\
\text { Right to security, right to work, Right to Dignity }\end{array}$ & $\begin{array}{l}\text { Right to work, Right to Health } \\
\text { Right to Life, Right to Culture, } \\
\text { Right to Dignity }\end{array}$ \\
\hline $\begin{array}{l}\text { 2. Health and } \\
\text { health care }\end{array}$ & $\begin{array}{l}\text { - Improved diagnostics } \\
\text { - Geographical access to care } \\
\text { - Increased safety in care } \\
\text { - Strengthening and precision in prevention } \\
\text { - Improved quality control of care } \\
\text { - Improving health promotion }\end{array}$ & $\begin{array}{l}\text { Right to health; Right to life } \\
\text { Right to information, right to work, Right to participate }\end{array}$ & $\begin{array}{l}\text { Right to work, Right to Health } \\
\text { Right to Culture, Right to Life } \\
\text { Right to Non-Discrimination }\end{array}$ \\
\hline 3. Mobility & $\begin{array}{l}\text { - Increased safety in transport } \\
\text { - Decrease in transport accidents } \\
\text { - Reducing mortality } \\
\text { - Likely cost reduction } \\
\text { Accessibility to economic, social and cultural goods }\end{array}$ & $\begin{array}{l}\text { Freedom of movement } \\
\text { Right to life, Right to Education, Right to Work, Right to } \\
\text { Health, Right to Safety and Security, Right to Association and } \\
\text { Meeting }\end{array}$ & $\begin{array}{l}\text { Right to Life, Right to Health } \\
\text { Right to Non-Discrimination } \\
\text { Freedom of movement }\end{array}$ \\
\hline $\begin{array}{l}4 . \\
\text { Environment }\end{array}$ & $\begin{array}{l}\text { - Refinement of predictions of natural disasters } \\
\text { - Improved civil protection control } \\
\text { - Improved environmental research } \\
\text { - Contribution to the protection of sensitive } \\
\text { environments } \\
\text { - Helping justice in the face of environmental damage } \\
\text { - Improved energy consumption }\end{array}$ & $\begin{array}{l}\text { Right to Life, Right to the Environment, Right to Health, Right } \\
\text { to Safety and Security, Right to Food, Right to Participation, } \\
\text { Right to Information }\end{array}$ & $\begin{array}{l}\text { Right to work, right to life, right to } \\
\text { health }\end{array}$ \\
\hline $\begin{array}{l}5 . \\
\text { Governance } \\
\text { and } \\
\text { Democracy }\end{array}$ & $\begin{array}{l}\text { - Strengthening the efficiency of public services } \\
\text { - Accessibility of services and procedures } \\
\text { - Better mobilization of resources and allocation } \\
\text { - Effective state management control }\end{array}$ & $\begin{array}{l}\text { Right to participation, right to information, Freedoms of } \\
\text { expression, association and assembly }\end{array}$ & $\begin{array}{l}\text { Privacy and data protection; Right to } \\
\text { safety and security, } \\
\text { Right to Life, Right to Dignity and } \\
\text { Right to Non-Discrimination }\end{array}$ \\
\hline $\begin{array}{l}\text { 6. Education } \\
\text { and Training }\end{array}$ & $\begin{array}{l}\text { - Increased personalization of education processes } \\
\text { - Solutions to the challenges of lifelong learning } \\
\text { - Progress in equity in training } \\
\text { - Accessibility to training programs } \\
\text { - Better contextualization of program content } \\
\text { - New forms of student-teacher collaboration }\end{array}$ & $\begin{array}{l}\text { Right to Education, Right to Participation, Right to Enjoy } \\
\text { benefits of Science, Right to Work }\end{array}$ & $\begin{array}{l}\text { Right to Non-Discrimination } \\
\text { Right to culture } \\
\text { Right to education } \\
\text { Right to work }\end{array}$ \\
\hline $\begin{array}{l}\text { 7. Banks and } \\
\text { Finance }\end{array}$ & $\begin{array}{l}\text { - Improved access to banking and financial systems } \\
\text { - Access to credit } \\
\text { - Data reliability } \\
\text { - Increased data processing capacity } \\
\text { - Improved prevention of fraud. }\end{array}$ & $\begin{array}{l}\text { Right to Education, Right to Life } \\
\text { Right to Health, Right to Work, } \\
\text { Right to enjoy the benefits of science }\end{array}$ & $\begin{array}{l}\text { Right to equal treatment before the } \\
\text { law } \\
\text { Right to Non-Discrimination } \\
\text { Right to work, Freedom of } \\
\text { association, demonstration or } \\
\text { assembly, Freedom of opinion }\end{array}$ \\
\hline 8. Economy & $\begin{array}{l}\text { - Increased productivity } \\
\text { - Technological innovations and social transformations } \\
\text { - Reducing social inequalities } \\
\text { - Reducing the cost of producing goods and services } \\
\text { - Automation of production processes }\end{array}$ & $\begin{array}{l}\text { Right to Life, Right to Enjoy the Benefits of Science, Right to } \\
\text { Work, Right to Food, Right to Health, Right to Education }\end{array}$ & $\begin{array}{l}\text { Right to work, Right to safety and } \\
\text { security of the person, Right to Non- } \\
\text { discrimination }\end{array}$ \\
\hline 9. Arts & $\begin{array}{l}\text { - Stimulating creativity in the arts (Music, painting...) } \\
\text { - Democratization of access to works of mind } \\
\text { - Massification of the production of works } \\
\text { - Improved copyright management processes } \\
\text { - Lower costs of producing works of art }\end{array}$ & $\begin{array}{l}\text { Right to work; The right to participate in cultural life; Right to } \\
\text { benefit from scientific progress and its applications; copyright }\end{array}$ & $\begin{array}{l}\text { Copyright } \\
\text { Right of access to cultural property } \\
\text { Right to Non-Discrimination } \\
\text { Right to work, }\end{array}$ \\
\hline $\begin{array}{l}\text { 10. Human } \\
\text { security }\end{array}$ & $\begin{array}{l}\text { - Improving the prevention of security threats } \\
\text { - Lower monitoring and response costs } \\
\text { - Improved decision-making tools (crossing sources) } \\
\text { - Saves time in enforcement of decisions } \\
\text { - Decision tracking and accountability } \\
\text { - Support for other sectors of social life (Justice...) }\end{array}$ & $\begin{array}{l}\text { Right to life, right to life and security, right to work, right to } \\
\text { development and right to peace, right to fair trial and due } \\
\text { process of law }\end{array}$ & $\begin{array}{l}\text { Right to life, right to life and safety, } \\
\text { Right to Health, Right to Non- } \\
\text { discrimination, right to work. }\end{array}$ \\
\hline
\end{tabular}


schisms; other are the results of random encounters; some develop in response to external conditions; others surface because of new and changing techniques or technologies. ${ }^{23}$

In an analytical perspective, the conditions for the emergence of a scientific discipline relate to the main dimensions characterizing a given set of knowledge, ie:

a. Extending specialization and increasing scientific professionalization

b. A set of knowledge operating within social and scientific

c. Organization around a "scientific community" whose members are in competition to produce knowledge and to exercise a control (peer-review) on each other research and teaching

d. Possession of a "self-reference": eg, widespread scientific recognition such as specific concepts and theories, specific glossaries, specific journals and books, citations by peers

e. Obtaining an academic recognition as a domain of research and teaching. ${ }^{24}$

For the time being, those conditions are not met by the domain "AI \& HRs". Indeed, it lacks specific academic recognition, demonstrates lack of professionalism, has only sparse specific research projects or teaching programs. Regarding training for example: teaching programs are rare, with but a few initiatives exist like the AI, HRs and migration program of the School of Law, at the Queen Mary London University ${ }^{25}$ or like the Master of Arts Human Rights in the Digital Society offered by the School of Governance, Law and Society of Tallinn University in Estonia. ${ }^{26}$

\section{Data Related Considerations}

Yet the present work shows that the seeds of a new scientific discipline have been planted and that it is important now to take care of this burgeoning tree and its emerging buds to ensure full disciplinary development through theoretical, organizational as well as institutional support and policies.

\section{Topics Investigated}

Indeed, the present study shows that there is a scientific literature covering various topics linking AI \& HRs, such as automatic weapon systems or big data, but also intellectual property or geographic localization and that many basic human rights are concerned such as the right to life, the right to security, the right to privacy, the right to justice, but also the right to health and the right to non-discrimination.

For example, the issue of the development and use of automatic weapon systems, dealt with in $24.3 \%$ of the articles reviewed, can be linked to the considerations of Sychev who reports on a letter signed by 16,000 personalities from around the world sounding the alarm of the dangers that these automatic weapon systems represent for the civilian populations and even for the survival of humanity, ${ }^{27}$ thus potentially infringing the right to life.

Another example: Big data (analytics), dealt with in $16.0 \%$ of the reviewed articles, is another critical issue regarding human rights. It may, for example, create "inherent risks and tensions around privacy", ${ }^{28}$ a fundamental human right. Indeed, as stated by some authors:

information technology is considered a major threat to privacy because it enables pervasive surveillance, massive databases, and lightning-speed distribution of information across the globe. ${ }^{29}$

\section{Increased Numbers of Publications}

The study also shows that there is an increasing scientific production over the decades with an exponential increase over the past five years, reflecting an increased research interest in investigating AI\&HRs from researchers from various disciplines (law, sociology, philosophy, engineering, etc.). This increase is also closely correlated to the technical developments of $\mathrm{AI}$ and its applications as highlighted by Anand. ${ }^{30}$ A growing interest shown by national and international institutions for the effects of AI on labor, safety or democracy might also have contributed to it as outlined in the Villani Report of $2018^{31}$ or in reports from various United Nations Agencies. ${ }^{32,33}$ 


\section{The Type of Studies}

Most articles were legal analyses. Interestingly 1 paper out of $6(16.5 \%)$ reported effects of AI in politics: be it considering the impact of AI on electoral processes, on public administration, on national security or on international geostrategy, eg:

- The emergence of robots as candidates for elective office and the possible manipulation of results constitute/might constitute some serious threats to the foundations of democratic societies. ${ }^{34}$

- The implementation of new technologies (robotics, artificial intelligence) raises legitimate concerns about its impact on public employment for example. ${ }^{35}$

- The international order might be determined by AI for decades to come, technology and power mutually reinforcing each other; thus, possibly transforming geopolitics through new relationships between spatiotemporal dimensions and immateriality. ${ }^{36}$

\section{Affiliations of Authors}

Not surprisingly the majority of authors are affiliated to American and British academic institutions as has been reported in scientific publications in general by authors like Gupta et al (US authors representing 28.6\% and British authors $8.9 \%$ of all science and technology publications); ${ }^{37}$ another factor possibly being the important AI investments made in the USA (445 billion euros in 2016) compared to other countries as reported by the Konrad Adenauer Foundation. ${ }^{38}$

\section{Impact of Al on HRs and Vice-Versa}

The extent of the potential impact of AI on HRs has been stressed in most analyzed papers, which is summed-up in Table 3. One could also argue that the respect of basic human rights might impact on the development and use/not use of AI: eg, the respect for the right to safety is an essential condition for the use of AI; the respect for the right to education enables the acquisition of the skills necessary to use $\mathrm{AI}$ in an appropriate way; failure to respect the right to information would constitute a barrier to the use of AI; infringements of freedoms of expression, association or assembly would limit the use of AI; and finally the failure to respect the right to work would potentially lead to the lack of income necessary for the acquisition and use of AI. The effects between AI \& HRs thus appear as bidirectional and synergistic.

However, these rights cannot simply be conceived from a normative perspective as a set of regulations governing the relationship between the individual and the state or vis-à-vis other states, but rather from a holistic angle which encompasses a strong social dimension. If a social movement is defined as a collective entity constituted by individuals who understand themselves to share some common interest and who also identify with one another, at least to some extent, these characteristics are not sufficient to capture the full gamut of this concept. To be complete, one must consider social movements as chiefly concerned with defending or changing at least some aspects of society and as having a strong reliance on mass mobilization, or the threat of it, as their main political sanction. ${ }^{39}$ Human rights are therefore not only a movement within the meaning of, for example, the civil rights movement, but also a theory-based social practice influencing it. ${ }^{40-42}$

These HRs impact AI and, in return, AI impacts HRs. We apprehend and depict this web of relationships through Figure 2. This diagram shows HRs as occupying a central stage and AI as an evolving reality around HRs, a reality whose characteristics and dimensions, depending on AI life stage (creation, production, commercialization, and utilization) are envisioned as having an impact on HRs and are also getting some type of retro-feedback.

\section{Challenges and Prospects of a Research Agenda}

The field of the AI and HRs is still in its infancy as evidenced by the results of this literature review. It is and will face many challenges that traditionally emerging disciplines have had to overcome, and which can be grouped as follows:

- The epistemological challenges related to the needs to create, assert, and consolidate its identity and unity as a scientific discipline and to clarify its fundamental concepts and delineate its scope of action. To this day, there is no accepted definition of this discipline which remains an important step in the construction of its identity and its unity. In the continuation of previous efforts ${ }^{39,42}$ in a neighboring field (health and human rights), the discipline of the AI and the HRs can be defined as a set of knowledge and multidisciplinary practices designed to analyze and to intervene 


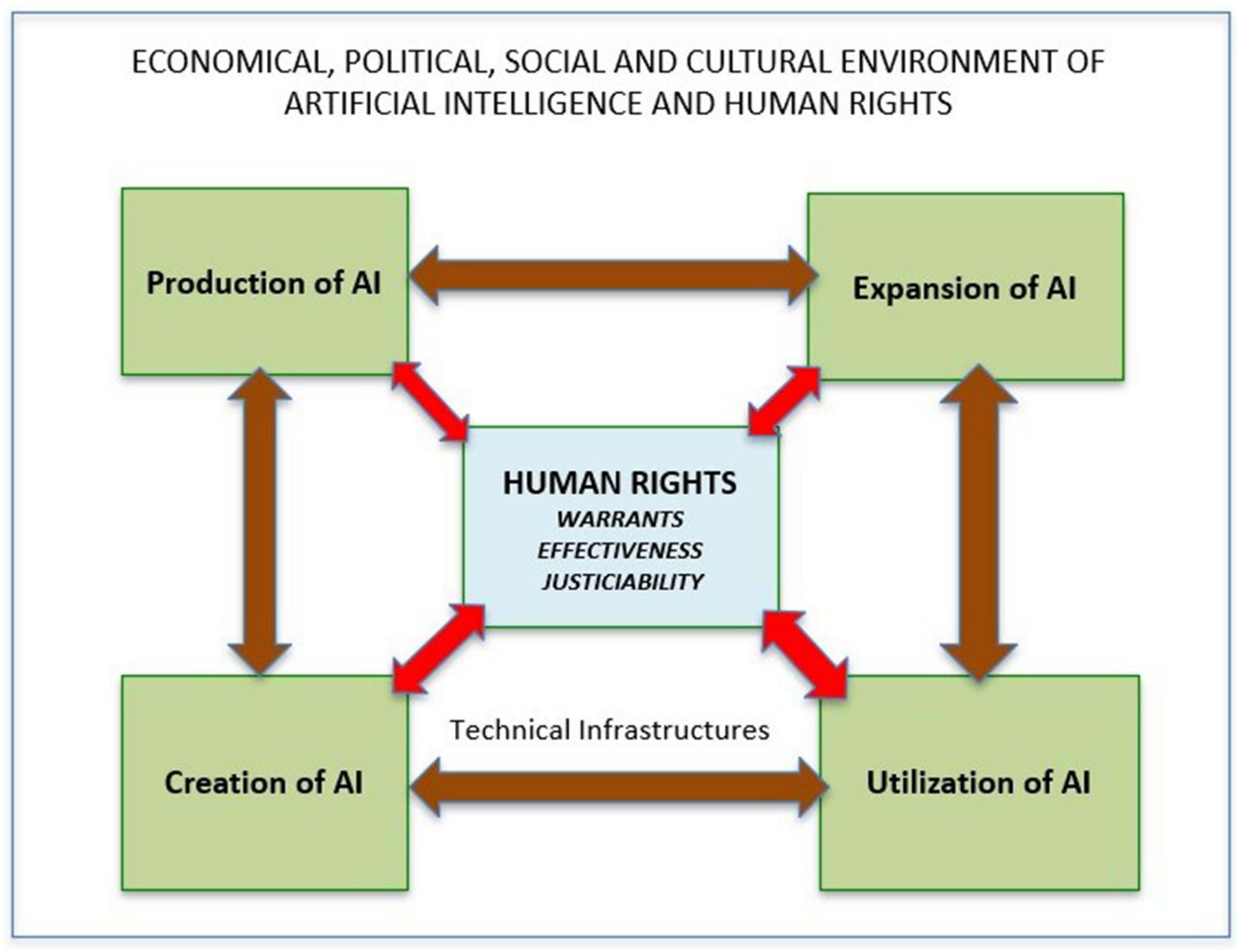

Figure 2 Conceptual framework of artificial intelligence and human rights and of their mutual and dynamic linkages.

in situations involving AI, human rights and social development, with the aim of improving the well-being of individuals and communities, by mobilizing the theoretical approaches and tools of several disciplines, including informatics, law, ethics, sociology, cognitive sciences and other sciences.

- The methodological challenges arising from the double origin of this new area (artificial intelligence science and legal and human rights sciences). This appears as a first obstacle to the construction of a common identity and to the advent of specific methods of the AI and HRs. This dualism has been highlighted by the review of the bulk of the studies we have analyzed; half of the studies being essentially of a legal nature, $25 \%$ of the others fall within the realm of humanities and social sciences. There are scant engineering studies that raise human rights issues.

- The challenges related to the institutionalization and professionalization, which are central concerns of stability of the research and training in this area. To day, there is neither a specialized research center in AI and HRs, nor an association or international network of professionals recognizing the links of their activities with this "discipline". It is essential at this juncture to develop an approach demonstrating both the identity, the object, the methods, the schools of thought and especially the political and social usefulness which can justify the academic recognition of the discipline, the provision of resources and the legitimation of its activities.

- Communication issues arise in terms of organization and operation of pioneering and leading journals specific to the discipline that can contribute to dissemination of produced knowledge, provision of space of exchanges between theorists and practitioners, stimulation of the social discussion relating to the object of the discipline. To this day, journals covering societal debates related to artificial intelligence (eg, AI \& Society: Knowledge, Culture and Communication, Frontiers in Artificial Intelligence), or law (European Journal of International Law, Yale Law Journal) and human rights (Human Rights Quarterly, Journal of Human Rights Practice) exist in which research on the AI and HRs may be published. To our knowledge however no scientific journal specifically dedicated to the link between AI/HRS exists.

- The challenge of the globalization of the research and experiences which is derived from the glaring imbalances between countries which are producers of technologies and those which are essentially consumers, and not represented in the countries where most of the research on AI and HRs are conducted. Among the 157 works 
analyzed in our study, 78 had been done by researchers from the USA whereas in comparison only 4 had been done by South African researchers, 1 by Russian and 1 by Brazilian; and this despite the fact that issues related to AI and HRs arise in those countries in a significant way.

In total, these five types of challenges may constitute strategic axes of a research agenda that can be detailed, developed, and enriched by research teams whose objectives cover the different themes identified in our review and those to come. One such objective would be an in-depth analysis at the legal level.

\section{Conclusion}

Our study has shown that this field of research at the crossroad between AI and HRs is not totally a "scientific desert". It is rather a dynamic field where researchers from several disciplines have already been operating at various degrees around issues arising from the application of AI in society.

Issues related to autonomous lethal weapons, the protection of the private sphere, discriminatory decision-making in the insurance and finance systems, intellectual property or legal personality of robots represent major concerns in a HRs perspective.

The analysis of conditions for the development of this "emerging discipline" has revealed epistemological and methodological challenges, in addition to issues of institutionalization and communication to which suitable answers would need to be found to anchor and consolidate the new "AI and HRs" discipline as a full-fledged member among existing scientific disciplines.

Finally, the serious threats and astonishing opportunities ${ }^{43,44}$ that those technologies carry, require "sustained attention and a permanent monitoring" of reports between AI and HRs. This includes, but goes beyond mere commercialization of the technology. ${ }^{44}$ It is our common responsibility.

\section{Disclosure}

The authors report no conflicts of interest for this work.

\section{References}

1. Want R. RFID: a key to automating everything. Sci A. 2004;290(1):56-65. doi:10.1038/scientificamerican0104-56

2. Saha D, Mukherjee A. Pervasive computing: a paradigm for the 21st century. IEEE Computer. 2003;36(3):25-31. doi:10.1109/MC.2003.1185214

3. Weiser M. Hot topics: ubiquitous computing. IEEE Computer. 1993;26(10):71-72. doi:10.1109/2.237456

4. Manyika J, Chui M, Bughin J, Dobbs R, Bisson P, Marrs A. Disruptive technologies: advances that will transform life, business, and the global economy. McKinsey Global Institute; 2013. Available from: http://www.mckinsey.com/business-functions/digital-mckinsey/our-insights/disruptivetechnologies. Accessed January 12, 2022.

5. United Nations Interregional Crime and Justice Research Institute (UNICRI). Available from: http://www.unicri.it/in_focus/on/UNICRI_Centre_ Artificial Robotics. Accessed January 12, 2022.

6. Nations Unies. Union Internationale de Telecommunications. United Nations Activities on Artificial Intelligence. Geneva: ITU Publications; 2018. Available from: https://www.itu.int/pub/S-GEN-UNACT-2018-1. Accessed January 12, 2022.

7. European Commission. High-level expert group on Artificial Intelligence; 2018. Available from: https://ec.europa.eu/digital-single-market/en/highlevel-expert-group-artificial-intelligence. Accessed January 12, 2022.

8. Conseil de l'Union Européenne. Plan coordonné pour le développement et l'utilisation de l'intelligence artificielle. Doc. 6177/19. Bruxelles: Conseilde 1'Union Européenne [Coordinated plan for the development and use of artificial intelligence. Doc. 6177/19. Brussels: Council of the European Union]; 2019. Available from: https://data.consilium.europa.eu/doc/document/ST-6177-2019-INIT/fr/pdf. Accessed January 12, 2022. French.

9. Commission Européenne. Lignes directrices en matiere d'ethique pour une IA digne de confiance. Bruxelles: Commission Européenne [(European Commission. Ethical Guidelines for Trustworthy artificial intelligence. Brussels: European Commission]; 2019. Available from: https://justicia. openum.ca/files/sites/181/2019/10/EthicsguidelinesfortrustworthyAI-FRpdf.pdf. Accessed January 12, 2022. French.

10. Beitz CR. The Idea of Human Rights. Oxford: Oxford Scholarship Online; 2012. DOI:10.1093/acprof:oso/9780199572458.001.0001.

11. Sucharitkul S. Multi-dimensional concept of human rights in international law. Notre Dame L. Rev. 2014;62:305.

12. Helleringer G, Kiteri G. Le rayonnement des droits de l'Homme et des droits fondamentaux en droit privé. Revue Internationale de Droit Comparé [The influence of human rights and fundamental rights in private law. International Journal of Comparative Law]. 2014;66(2):283-336. French. doi:10.3406/ridc.2014.20388

13. Henette-Vauchez S, Roman D. Droits de l'homme et libertés fondamentales [Human rights and fundamental freedoms]. Paris: Dalloz (Hypercours); 2020. French

14. Langford M, ed. Social Rights Jurisprudence. Emerging Trends in International and Comparative Law. Cambridge: Cambridge University Press; 2008.

15. Lawson EH, ed. Encyclopedia of Human Rights. London: Taylor \& Francis; 1996. 
16. Liu HY, Zawieska K. From responsible robotics towards a human rights Regime oriented to the challenges of robotics and artificial intelligence. Ethic Inf Technol. 2017;22:1-13.

17. Chakraborty S, Bhojwani R. Artificial intelligence and human rights: are they convergent or parallel to each other? Novum Jus. 2018;12(2):13-38. doi:10.14718/NovumJus.2018.12.2.2

18. Reisse M. Human rights and artificial intelligence: an urgently needed agenda. Hum Rights Q. 2019;41:1-16. doi:10.1353/hrq.2019.0000

19. Liberati A, Altman DG, Tetzlaff J, et al. The PRISMA statement for reporting systematic reviews and meta-analyses of studies that evaluate healthcare interventions: explanation and elaboration. BMJ. 2009;339:b2700. doi:10.1136/bmj.b2700

20. Altman DG, Moher D. [Developing guidelines for reporting healthcare research: scientific rationale and procedures.]. Med Clin. 2005;125(Suppl 1):8-13. Spanish. doi:10.1016/S0025-7753(05)72203-X

21. Leclerc M. La notion de discipline scientifique et ses enjeux sociaux [The notion of scientific discipline and its social issues]. Politique. 1998;15:23-51. French.

22. Affergan F, Valade B. Discipline. In: Mesure S, Savidan P, editors. Le Dictionnaire Des Sciences Humaines [The Dictionary of the Humanities]. Paris: Presses Universitaires de France; 2006:278-284. French.

23. Boure R. Réflexions autour de l'institutionnalisation des disciplines [Reflections on the institutionalization of disciplines]. Communication. 2005;24 (1):9-37. French. doi:10.4000/communication.3236

24. Artificial intelligence, human rights and migration. School of Law, Queen Mary London University. Available from: https://www.qmul.ac.uk/law/ postgraduate/courses $/ 1 \mathrm{~lm} / \mathrm{modules} / 1 \mathrm{~lm} /$ items/solm240-artificial-intelligence-human-rights-and-migration.html. Accessed January 12, 2022.

25. Master of arts human rights in the digital society. Tallinn University: School of Governance, Law and Society. Available from: https://www.tlu.ee/ en/yti/human-rights-digital-society. Accessed January 12, 2022.

26. Sychev V. La menace des robots tueurs, Le Courrier de l'Unesco, Intelligence artificielle Promesses et menaces [The threat of killer robots, The Unesco Courier, Artificial Intelligence Promises and Threats]. Paris. 2018:25-27. French.

27. Latanero M. Big data analytics and human rights. In: Land MK, Aronson JD, editors. New Technologies in Human Rights Laws and Practice. Cambridge University Press; 2018:149-161.

28. Nissenbaum H. Privacy in Context: Technology, Policy and the Integrity of Social Life. Palo Alto, CA: Stanford University Press; 2010.

29. Anand S Artificial intelligence - literature review. India: The Centre for Internet Society; 2017. Available from: https://cis-india.org/internetgo vernance/files/artificial-intelligence-literature-review. Accessed January 12, 2022.

30. Villani C, Schoenauer M, Bonnet Y, et al. Donner un sens à l'intelligence. Pour une stratégie nationale et européenne [Making intelligence. For a national and European strategy]; 2018. Available from: https://www.vie-publique.fr/rapport/37225-donner-un-sens-lintelligence-artificielle-pourune-strategie-nation. Accessed January 12, 2022. French.

31. United Nations Interregional Crime and Justice Research Institute. UNICRI centre for artificial intelligence and robotics. The Hague, The Netherlands; 2019. Available from: http://www.unicri.it/in focus/on/UNICRI Centre Artificial Robotics. Accessed January 12, 2022.

32. International Telecommunication Union. United nations activities on artificial intelligence. Geneva: ITU; 2018. Available from: https://www.itu.int/ dms_pub/itu-s/opb/gen/S-GEN-UNACT-2018-1-PDF-E.pdf. Accessed January 12, 2022.

33. Kane TB. Artificial intelligence in politics: establishing ethics. IEEE Technol Soc Mag. 2019;38(1):72-80. doi:10.1109/MTS.2019.2894474

34. Reis J, Santo P, Melão N. Influence of artificial intelligence on public employment and its impact on politics: a systematic literature review. Braz J Oper Prod Manag. 2021;18(3):1-22. doi:10.14488/BJOPM.2021.010

35. Miailhe N. The geopolitics of artificial intelligence: the return of empires. Polit Étrang. 2018;I:105-117. doi:10.3917/pe.183.0105

36. Gupta BM, Dhawan SM, Gupta RP. Indicators of S\&T publications output: developed versus developing countries. DESIDOC J Libr Inf Technol. 2007;27(1):5-16.

37. Groth OJ, Nitzberg M, Zehr D, Straube T, Kaatz-Dubberke T. Comparison of national strategies to promote artificial intelligence. Report. Berlin: Konrad-Adenauer-Stiftung; 2019.

38. Mpinga EK, Leslie L, Chastonay P. Health and human rights: epistemological status and perspectives of development. Med Health Care Philos. 2011;14(3):237-247. doi:10.1007/s11019-011-9310-7

39. Stammers N. Social movements and the social construction of human rights human rights quarterly. Hum Rights Q. 1999;21(4):980-1008

40. Fields A, Narr W. Human rights as holistic concept. Hum Rights Q. 1992;14(1):1-20. doi:10.2307/762549

41. Donnelly J. Universal Human Rights in Theory and Practice. Ithaca: Cornell University Press; 1989.

42. Yudkowsky E. Artificial intelligence as a positive and negative factor in global risk. In: Bostrom N, Cirkovic MM, editors. Global Catastrophic Risks. New York: Oxford University Press; 2008.

43. Muehlhauser L, Salamon A. Intelligence explosion: evidence and import. In: Eden A, Moor J, Søraker J, Steinhart E, editors. Singularity Hypotheses. The Frontiers Collection. Berlin, Heidelberg: Springer; 2102.

44. Hou R. The commercialisation of internet-opinion management: how the market is engaged in state control in China. New Media Soc. 2020;22 (12):2238-2256. doi:10.1177/1461444819889959

\section{Publish your work in this journal}

The Journal of Multidisciplinary Healthcare is an international, peer-reviewed open-access journal that aims to represent and publish research in healthcare areas delivered by practitioners of different disciplines. This includes studies and reviews conducted by multidisciplinary teams as well as research which evaluates the results or conduct of such teams or healthcare processes in general. The journal covers a very wide range of areas and welcomes submissions from practitioners at all levels, from all over the world. The manuscript management system is completely online and includes a very quick and fair peer-review system. Visit http://www.dovepress.com/testimonials.php to read real quotes from published authors.

Submit your manuscript here: https://www.dovepress.com/journal-of-inflammation-research-journal 